\title{
THE TIME FACTOR IN P32-INDUCED MUTATIONS IN MALE DROSOPHILA
}

\author{
A. J. BATEMAN
}

British Empire Cancer Campaign Research Fellow, Christie Hospital and Holt Radium Institute, Manchester, U.K. *

\section{INTRODUCTION}

Received 18.x.54

Following an earlier indication (Bateman and Sinclair, 1950) that the ratio of visible mutations to recessive lethals on the sex chromosome was higher for ingested Phosphorus-32 than for X-rays, the author

TABLE 1

Comparison of mutagenic action of $P^{32}(50 \mu C$ per culture tube containing larva) and $X$-rays ( $4000 r$ to newly emerged adults)

\begin{tabular}{|c|c|c|c|c|c|c|}
\hline \multirow{2}{*}{ Mutation } & \multirow{2}{*}{ Remarks } & \multicolumn{2}{|c|}{ Actual values } & \multicolumn{2}{|c|}{ Percentages } & \multirow{2}{*}{$\begin{array}{c}\text { Probability } \\
\text { of } \\
\text { difference }\end{array}$} \\
\hline & & $\mathbf{P}^{32}$ & X-rays & $\mathbf{P}^{32}$ & X-rays & \\
\hline Dominant lethals * . & As indicated by fertility & $\cdots$ & $\cdots$ & $\cdots$ & $\cdots$ & $\ldots$ \\
\hline & $\begin{array}{l}\text { No. of daughters of } \\
\text { Muller- } 5\end{array}$ & $4 \cdot 7$ & $10 \cdot 3$ & 87 & 71 & $\cdots$ \\
\hline & $\begin{array}{c}\text { No. of sons of } \\
\text { attached- } X y \text { 우우 }\end{array}$ & $13 \cdot 6$ & $20 \cdot 5$ & 43 & 13 & ... \\
\hline $\begin{array}{l}\text { Sex - linked recessive } \\
\text { lethals }\end{array}$ & Muller-5 matings & $11 / 130$ & $13 / 199$ & $8 \cdot 5$ & $6 \cdot 5$ & 0.5 \\
\hline Visibles . . . & , & $3 / 130$ & 2/199 & $2 \cdot 3$ & $1 \cdot 0$ & $\cdots$ \\
\hline Deleted $X$ 's . & $\begin{array}{l}\text { Non- } y \text { daughters from } \\
\text { attached- } X y \text { 우. All } \\
\text { data }\end{array}$ & $40 / 1520$ & $15 / 1584$ & $2 \cdot 6$ & $1 \cdot 0$ & $<0.001$ \\
\hline & $\begin{array}{c}\text { 1st hatchings from } \\
\text { 1st matings }\end{array}$ & $18 / 693$ & $2 / 735$ & $2 \cdot 6$ & 0.3 & $<0.001$ \\
\hline "Probable" visibles $\dagger$ & From attached- $X \boldsymbol{y}$ 우우 & $22 / 1520$ & $16 / 15^{84}$ & $1 \cdot 4$ & $1 \cdot 0$ & $<0.3$ \\
\hline
\end{tabular}

* For dominant lethals " actual values" are fertility figures. "Percentages" are the percentage by which these fall below the control value ; theoretically the percentage rate of dominant lethality.

$\uparrow$ These are judged on phenotype alone since a very high proportion are sterile and cannot be tested genetically. The figures will therefore include some autosomal dominants and some non-heritable variants as well as genuine sex-linked recessives.

has made a direct comparison of the mutation spectra produced by the two mutagens. The mutation spectrum is partly dependent on dose and one should therefore endeavour to compare dosages of $\mathbf{P}^{32}$

* The experiments on which this paper is based were carried out at the John Innes Horticultural Institution, Hertford. 
and $\mathrm{X}$-rays which give the same yield of a standard fraction, such as sex-linked recessive lethals.

In the first comparison (table I) treated males were mated for three days, though some were re-mated for another three days. The $\mathbf{P}^{32}$ gave slightly more sex-linked lethals (not significantly so); an apparently higher rate of dominant lethals, measured indirectly from fertility; and a highly significant excess of hyperploidy due to supernumerary deleted $X$ 's. The X-ray data were very heterogeneous in respect of this mutation. If we exclude the second matings and the later hatchings from the first, the discrepancy between the two sources of radiation becomes very striking : $2 \cdot 6$ per cent. for $\mathrm{P}^{32}$ as against 0.3 per cent. for X-rays. Finally there is a non-significantly higher incidence of "probable" visible mutants from the $y$ attached- $X$

\section{TABLE 2}

Change of mutation rate with successive samples of sperm:

$P^{32}$ and $X$-rays compared

\begin{tabular}{|c|c|c|c|c|c|c|c|c|}
\hline \multirow{3}{*}{$\begin{array}{l}\text { Days' } \\
\text { mating }\end{array}$} & \multicolumn{6}{|c|}{$\begin{array}{c}\text { Dominant lethals * } \\
\text { (per cent. eggs hatching) }\end{array}$} & \multicolumn{2}{|c|}{$\begin{array}{c}\text { Sex linked recessives } \\
\text { (per cent. lethals }+ \\
\text { visibles) }\end{array}$} \\
\hline & \multicolumn{3}{|c|}{$\mathrm{P}^{32}$} & \multicolumn{3}{|c|}{ X-rays } & $\mathbf{P}^{\mathbf{2}}$ & X-rays \\
\hline & $\underset{I}{\text { Series }}$ & $\begin{array}{l}\text { Series } \\
2\end{array}$ & $\begin{array}{c}\text { Series } \\
3\end{array}$ & $\begin{array}{c}\text { Series } \\
!\end{array}$ & $\begin{array}{l}\text { Series } \\
2\end{array}$ & $\begin{array}{c}\text { Series } \\
3\end{array}$ & \multicolumn{2}{|c|}{$\begin{array}{c}3 \text { series } \\
\text { combined } †\end{array}$} \\
\hline $\begin{array}{c}1 \\
4 \\
6 \text { and } 7 \\
10 \\
13 \\
16\end{array}$ & $\begin{array}{c}9 \cdot 2 \\
\ldots \\
10 \cdot 8 \\
\ldots \\
\ldots \\
\ldots\end{array}$ & $\begin{array}{l}26 \cdot 2 \\
21 \cdot 7 \\
27 \cdot 8 \\
61 \cdot 5 \\
72 \cdot 4 \\
66 \cdot 4\end{array}$ & $\begin{array}{r}1 \cdot 6 \\
0.0 \\
5 \cdot 2 \\
12 \cdot 2 \\
41 \cdot 3 \\
59 \cdot 7\end{array}$ & $\begin{array}{l}40 \cdot 6 \\
\cdots \\
5 \cdot 2 \\
\cdots \\
\cdots \\
\cdots\end{array}$ & $\begin{array}{r}52 \cdot 2 \\
41 \cdot 3 \\
4 \cdot 6 \\
12 \cdot 6 \\
70 \cdot 0 \\
60 \cdot 1\end{array}$ & $\begin{array}{c}47 \cdot 1 \\
22 \cdot 7 \\
2 \cdot 8 \\
51 \cdot 1 \\
\ldots \\
\ldots\end{array}$ & $\begin{array}{r}14 \cdot 0 \\
4 \cdot 7 \\
6 \cdot 1 \\
39 \\
3 \cdot 3 \\
0 \cdot 0\end{array}$ & $\begin{array}{c}8 \cdot 5 \\
10.8 \\
14.3 \\
7.4 \\
0.0 \\
\ldots\end{array}$ \\
\hline
\end{tabular}

* Control value 70 per cent.

$\dagger$ The three $\mathrm{P}^{32}$ series are obviously heterogeneous, so that variation with time has little meaning.

matings. The high sterility of suspected mutant males means that one can make use of them only by guessing at their genetic nature. The total will thus include some autosomal dominants as well as some non-genetic variants.

The hyperploidy results indicated that comparisons of the mutagens would depend on the time of sampling of the sperm. So a second experiment was set up in which sperm was sampled every three or five days over an extended period (table 2).

It was at once apparent that the effect of mating sequence was quite different in the two treatments. X-rays produced a peak mutation rate for dominant lethals after the first few days, followed by a drop to the control value, as found by Lüning (I952) and Auerbach (1954). $\mathbf{P}^{32}$, on the other hand, showed a constant rate for between 
seven and ten days, after which it fell to the control level. There is a suggestion of the same effects with sex-linked recessives. Incidentally, pooling the data of the two experiments gives confirmation of a higher ratio of visibles to lethals with $\mathbf{P}^{32}$. The ratios were 7:22 for $\mathrm{P}^{32}$ and 6:43 for X-rays, though the difference is not statistically significant $(\mathbf{P}=0 \cdot 2)$. Only those visibles are included which are strictly comparable to the lethals in that they arose in the Muller-5 matings.

The experiment to be described investigates further, and analyses, the variation in mutation rate for one specific type of mutation, between successive sperm batches following the ingestion of $\mathbf{P}^{32}$ by larvæ.

\section{FEEDING}

The normal medium was made up with molasses, oatmeal and agar, which was then yeasted with a yeast suspension. The parents were added from mating tubes and shaken out again after 24 hours laying. Twenty-four hours later still, when all hatchable eggs had hatched and larvæ were in their first instar, $\mathbf{P}^{\mathbf{8 2}}$ solution was added at 4 drops per tube from a calibrated syringe needle ( 4 drops : $0.03 \mathrm{ml}$.). The solution was placed well in the middle of the food surface to avoid seepage down between food and glass. Even then, however, there is considerable variation in activity between larvæ from the same tube, presumably owing to variation in activity over the food surface. When bottles were used the volume of $\mathbf{P}^{\mathbf{3} 2}$ solution was increased five times to correspond to the increased surface area of the food.

It had been found that larger volumes of solution per tube tended to overflow between glass and food, causing an unreliable distribution of activity. If the volume was increased to as much as $0.5 \mathrm{ml}$. many larvæ were drowned. The dose per tube was $30 \mu \mathrm{C}$ at the time of application ( $150 \mu \mathrm{C}$ for bottles). Analysis of the food medium showed that most of the activity was in the top layer where the larvæ fed.

\section{TYPE OF MUTATION}

The "dominant lethal " method for studying mutation rates as used by many workers (e.g. Lüning, 1952) is rather insensitive owing to the variable proportion (usually o-1o per cent. but sometimes much higher) of non-hatching eggs in the controls, and the ever-present danger of confusing dominant lethality with unfertilised eggs. An alternative method which gives the mutation rate in the first generation has been developed.

This involves scoring the frequency of non-yellow (hyperploid) daughters of yellow attached- $X$ females mated to treated wild-type males. The sole source of confusion is the low spontaneous rate (about one in a thousand) of production of non-yellow daughters by " detachment" of the attached- $X$ 's.* These are readily recognised by breeding tests. When the $y^{+}$-bearing fragment of the $X$ is below a critical size the hyperploid females are fertile and their breeding behaviour is characteristic.

The advantages of the method are : the unambiguous recognition

* The author had not appreciated the frequency of detachment until the completion of the experiment so the above distinction was not made. Most of the non-yellow daughters after nine days' mating are probably the results of detachment. 
of non-yellow females, even to an untrained observer ; control values practically zero, especially after elimination of detached- $X$ 's ; and recognition in the first generation (though breeding for a further generation is necessary to detect the detached- $X$ females).

The recovered hyperploids have arisen by breakage of the $X$ chromosome in two places followed by rearrangement, which produces an acentric and a centric fragment. The centric fragment will almost certainly carry the $y^{+}$allele which is very close to the left end. Females carrying fragments above a certain size die in the same way that triplo- $X$ females die in normal attached- $X$ matings. Very occasionally these "super-females" will be found in cultures, when they are recognised by their small size.

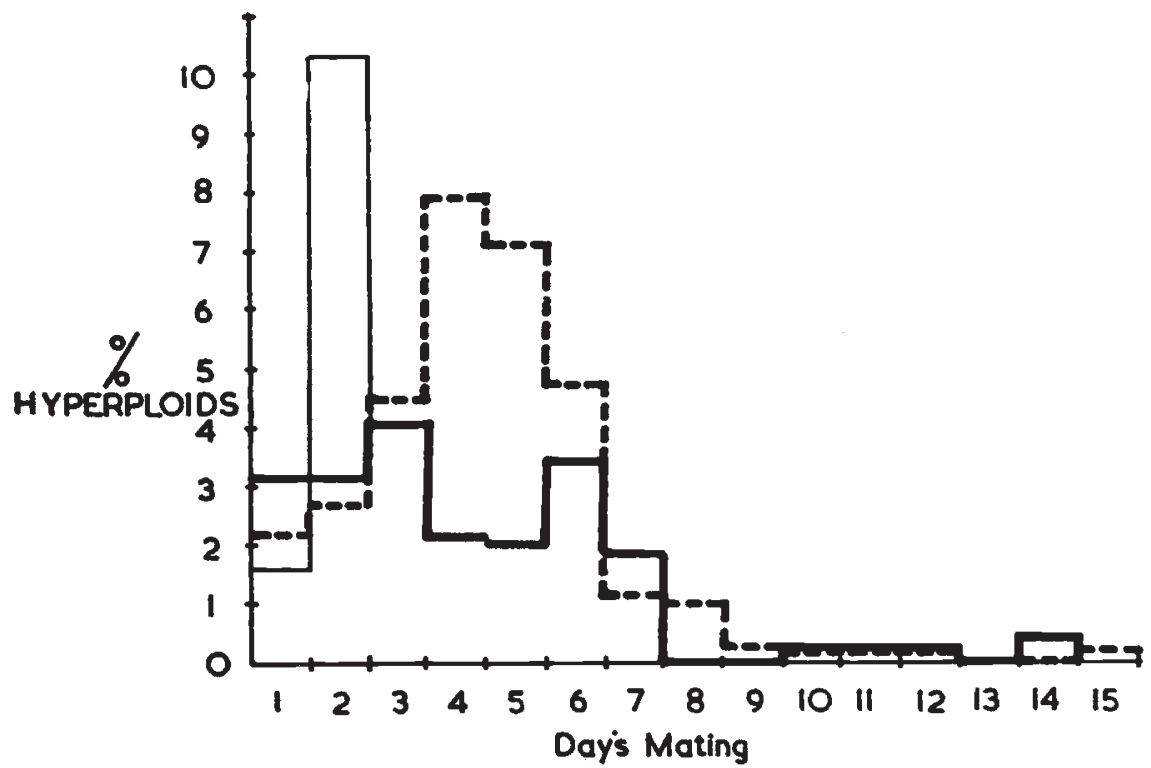

Fig. 1.-Mutation rate measured as the percentage of hyperploid daughters according to the day of mating in two series.

Entire line : $\$ 07$ pupating out of active medium.

Broken line : $\delta \delta$ pupating in active medium.

Owing to the erratic value for the 2nd day of the first series (due to small size of sample) the weighted mean for the first two days is also shown. The difference between the two series is presumed to be the effect of external radiation on the pupa.

Hyperploids could also arise through $X-Y$ or $X$-autosome translocations, but only following breakage in diploid cells.

The primary cause of hyperploids, chromosome breakage, is also responsible for the great majority of dominant lethals. Results based on hyperploidy should therefore parallel those expected from dominant lethal studies, only they will be more reliable. One important difference which must be borne in mind is that since hyperploids are dependent on a minimum of two breaks per chromosome, (two-event phenomena) their frequency will be more sensitive to variation in dosage or effective dosage (sensitivity times dosage). 


\section{OBSERVED RATE}

The treated males consisted of two groups, those which pupated out of the active medium and were transferred on pupation to inactive tubes, and those which pupated in the medium. The internally generated radiation would be the same in both groups, but the external radiation would be greater and over a longer period in the second group. Unetherised males were mated singly when one day old to 5 yellow attached- $X$ virgin females, also unetherised. Five fresh virgin unetherised females were supplied every day except for one two-day period from the IIth to $13^{\text {th }}$ days. This high number of females was partly owing to the low mating frequency of females of this stock, but also to ensure that sperm was utilised as it matured.

TABLE 3

Variation of hyperploid production with day of mating and site of pupation

\begin{tabular}{|c|c|c|c|c|c|c|}
\hline \multirow{2}{*}{$\begin{array}{l}\text { Day of } \\
\text { mating }\end{array}$} & \multicolumn{3}{|c|}{ Pupæ out of medium } & \multicolumn{3}{|c|}{ Pupx in active medium } \\
\hline & $\begin{array}{c}\text { Non-yellow } \\
\text { ọ? }\end{array}$ & $\begin{array}{c}\text { Total } \\
\$ \uparrow\end{array}$ & $\begin{array}{l}\text { Per cent. } \\
\text { non-yellow }\end{array}$ & $\begin{array}{c}\text { Non-yellow } \\
\text { कq }\end{array}$ & $\begin{array}{c}\text { Total } \\
\text { ọ? }\end{array}$ & $\begin{array}{l}\text { Per cent. } \\
\text { non-yellow }\end{array}$ \\
\hline I & 2 & 126 & $x \cdot 6$ & 4 & I 78 & $2 \cdot 2$ \\
\hline & 3 & 29 & 30:3 & 6 & 222 & $2 \cdot 7$ \\
\hline First two & 5 & 155 & $3 \cdot \mathbf{2}$ & & & $\cdots$ \\
\hline 3 & 6 & 149 & 4.0 & 8 & 180 & $\begin{array}{l}4.4 \\
7.8\end{array}$ \\
\hline $\begin{array}{l}4 \\
5\end{array}$ & 3 & $\begin{array}{r}40 \\
148-10\end{array}$ & $2 \cdot 0$ & 5 & $\begin{array}{l}77 \\
70\end{array}$ & 7.3 \\
\hline 6 & 4 & 116 & 3.4 & I. & $23^{6}$ & $4 \cdot 7$ \\
\hline 7 & 4 & 225 & 1.8 & 2 & 174 & I'I \\
\hline 8 & o & 337 & $0 \cdot 0$ & 8 & 785 & r.o \\
\hline 9 & o & 260 & 0.0 & 4 & 1012 & 0.2 \\
\hline Io & I & 404 & $0 \cdot 2$ & i & 995 & $0 \cdot \mathbf{I}$ \\
\hline I I & I & 6 ro & 0.2 & 2 & 1463 & 0.1 \\
\hline 13 & 0 & $54^{\circ}$ & 0.0 & 0 & 784 & 0.0 \\
\hline 14 & I & 252 & 0.4 & o & 572 & $0 \cdot 0$ \\
\hline 15 & 0 & 185 & $0 \cdot 0$ & I & 825 & $0 \cdot x$ \\
\hline
\end{tabular}

The results are given in table 3 and fig. I. By an unfortunate accident the formally necessary control matings were lost, but the incidence of non-yellow daughters from unirradiated matings is always very low. The effects of irradiation from the medium during pupation appear to be confined to three days, the $4^{\text {th }}$ to 6th days' mating, but especially the $4^{\text {th }}$ and $5^{\text {th, although pupation extends over four }}$ days. During these two days the increase in mutation due to external radiation of the pupa is about equal to that due to all other sources.

The general shape of the curves in fig. I is not, however, quite as had been expected. Excluding the effects of external radiation of the pupæ, there is a gradual fall with each day's laying up to the 9th or Ioth day. Yet the effect of $\mathbf{P}^{32}$ had been expected to be cumulative, the dose increasing continuously with the decay of the $\mathbf{P}^{32}$. The explanation for this discrepancy follows. 


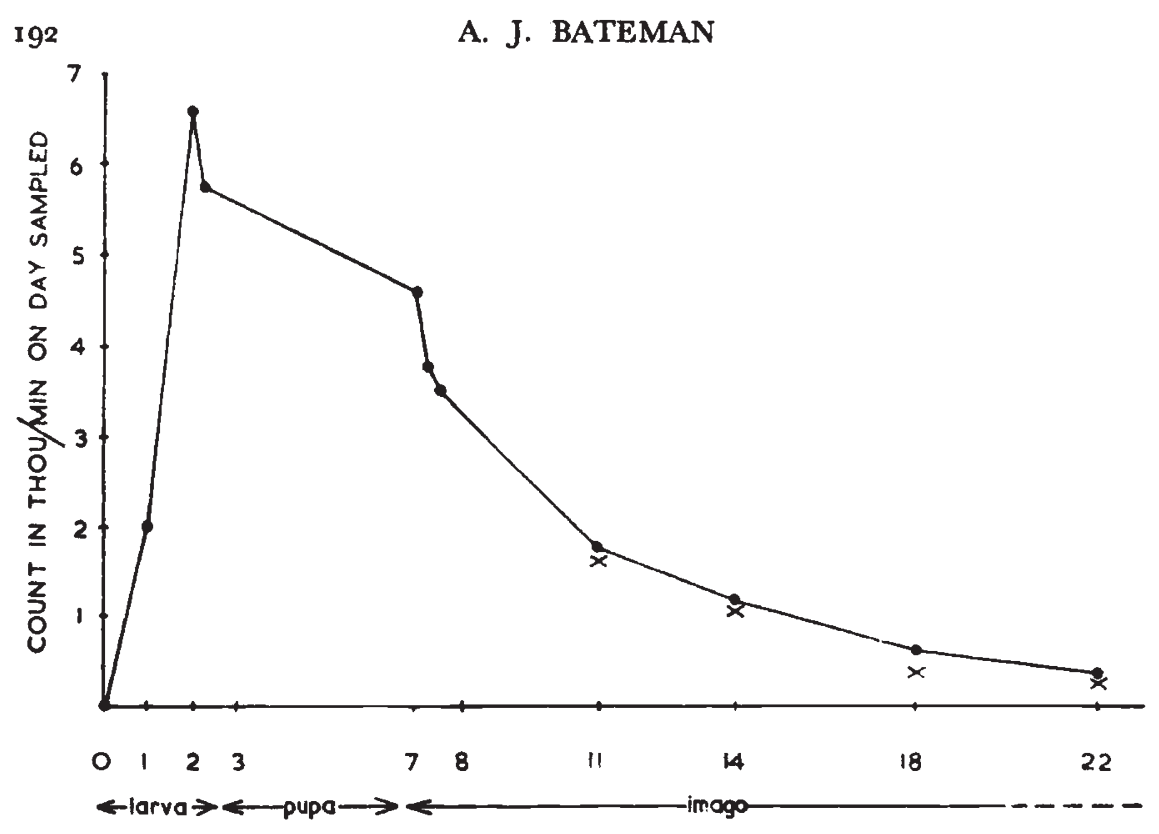

DAYS FROM AODITION OF P-32

(a)

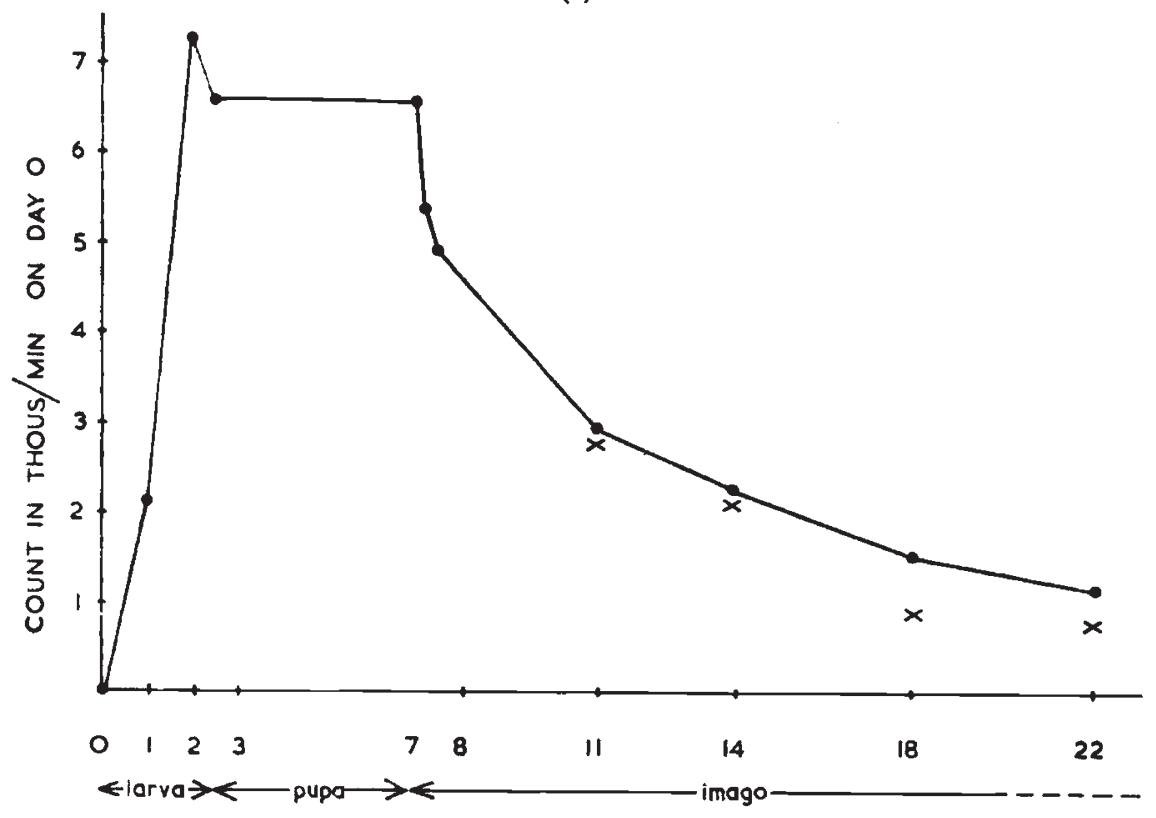

DAYS FROM ADOITION OF P-32

(b)

Fig. 2.-Mean activity of larva, pupe, and imagos of male Drosophila with successive, days from addition of $\mathbf{P}^{32}$ to the medium. Points joined by the line are for virgin males, crosses for mated males.

(a) Count in thousands per minute at time of sampling.

(b) Count as at the moment of addition of $\mathrm{P}^{32}$ (i.e. without radioactive decay). 


\section{VARIATION OF P32 CONTENT WITH TIME}

The activity of larvæ, pupx, newly emerged imagos and imagos aged on inactive medium were measured with a Geiger counter. The results shown in fig. 2 are the means for flies from three treatment bottles. Fig. $2 a$ shows the activity on the date sampled in thousands per minute, and $2 b$ the counts as they would have been at a constant time, the date on which the $\mathbf{P}^{32}$ was added to the medium. Thus the variation shown in fig. $2 b$ is exclusive of radioactive decay. Mostly it is due to excretion. There is an additional loss from mated males which is almost certainly due to the phosphorus transferred in the sperm. Counts of females, previously inactive, following a single copulation with an active male, have shown the transfer of as much as 5 per cent. of the male's activity in the form of sperm. The loss rate through excretion is very similar to that found by King (1953) following adult feeding.

The very rapid loss of $\mathbf{P}^{32}$ from adults will reduce the expected cumulative effect of radioactive decay, but it cannot eliminate it or even reverse it as appears from the graph of fig. $\mathbf{r}$. This must be due to the variation in sensitivity to mutagens during spermatogenesis.

\section{SENSITIVITY OF DEVELOPING SPERM}

The best evidence available on the variation in sensitivity is in the work of Lüning (1952) who followed the incidence of dominant lethals in consecutive sperm batches following a single dose of X-rays to the adult male. Maximum sensitivity was found in spermatids 6-7 days from maturity. Earlier stages became rapidly less sensitive (at least for recoverable mutations) until no mutations were found in germ cells irradiated eleven or more days prior to maturity. Caution should be used in applying these results to all sperm, because it is doubtful whether sperm matures at the same rate in adults as in larvæ and pupæ.

Thus, according to Kerkis (1933), 24-hour larvæ (seven days to emergence of imago) have only spermatogonia in their testes. Primary spermatocytes do not appear until larvæ are 50 hours old. Meiosis has not begun even by 96 hours (just prior to pupation, which lasts four days), though there are then large numbers of mature spermatocytes. Twenty-four hours later there are already morphologically mature spermatozoa and all stages of maturation divisions. The newly emerged male has relatively few immature stages in his testes, the bulk being mature sperm. Thus the oldest sperm in a male mating within 24 hours of emergence is less than five days from meiosis. It would appear, therefore, that either the mutation sensitive stage identified by Lüning is pre-meiotic, or sperm maturing throughout in the adult takes two to three days longer than the first sperm batches. The latter seems the likelier explanation.

Granted that there is an immature, highly radiosensitive stage in spermatogenesis, it becomes necessary to infer its timing directly 
from our own data. The difference between the two curves of fig. I tells us that sperm which was in the hypersensitive stage during pupation was used on the $4^{\text {th }}$ and $5^{\text {th }}$ days' mating. The interval between the middle of pupation and the $4^{\text {th }}$ to $5^{\text {th }}$ sperm batches is seven to eight days. Thus, after all, the interval from hypersensitivity to maturity estimated from our own data, though estimated for sperm maturing during pupation, is the same as Lüning's.

\section{ABSORPTION OF INTERNALLY GENERATED RADIATION}

The prediction of absolute mutation rates would involve estimation of the roentgen equivalent dose at the testes. This is not at present possible. The mean whole-body dose, however, can be estimated from the percentage absorption of internally generated radiation.

Bateman and Sinclair (loc. cit.) tried to estimate this on a purely physical basis, using as a model Drosophila a sphere of I c.mm. volume. They estimated that with uniform distribution of the activity the absorption would be $3^{8}$ per cent. There can now be little doubt that this was a considerable over-estimate.

King (1952) made two estimates. He used a more refined geometrical model of the fly, considering it as three spheres, head, thorax and abdomen, and made direct measurements of the distribution of activity between these three divisions. Summing the absorption to be expected on physical grounds in the three spheres, he estimated the total internal absorption as 12.55 per cent. However, so many assumptions have to be made (of which the one most likely to be erroneous is that of uniformity of distribution) that a direct measurement of absorption, however crude, is much to be preferred. King ashed male flies, which yielded a mass which was 3 per cent. of the fresh weight and obtained an increase of 9.5 per cent. in the count. Neglecting absorption by the ash, the absorption by the fresh body will be $9 \cdot 5 / \log \cdot 5: 8 \cdot 7$ per cent.

We have now made further attempts at direct measurement. Newly hatched males fed as larvæ were counted fresh and then divided into two batches, each of ro flies. The first was squashed flat in a fold of paper which was then opened out and recounted (under these conditions there was very rapid drying). The count was increased by 9.2 per cent. The second batch was digested in sulphuric acid and counted with a liquid counter calibrated against the usual dry counter. This should have given the total activity. However, the results were very erratic (the increase in count varied from + I per cent. to -13 per cent. !) and the method is evidently unsuitable. Perhaps the digestion was too incomplete. Comparison with King's results indicates that squashing the fly on paper gives as complete a count as any other method, perhaps because the fly is then in a very thin dry film. It gives us an estimate of absorption in the fresh fly of 8.4 per cent. compared with King's estimate of 8.7 per cent. 
According to King, the $\mathbf{P}^{32}$ in the head and thorax can be ignored in estimating the radiation to the testes. The abdomen generally contains about half the total activity.

\section{PREDICTION OF MUTATION RATE}

Without concerning ourselves with absolute mutation rates, the relative magnitudes in different batches of sperm will be given by the sum of the products of the radiation sensitivity at each stage of maturation and the counting rates of the sources of radiation. These sources are ingested $\mathrm{P}^{32}$ as given in fig. $2 a$, and external radiation, which extends to the third day for flies removed from the active medium at pupation and to the seventh day for those pupating in the medium.

Counts of the surface of the food medium and pupæ show that the specific activity of the pupæ is four times that of the food. Thus if the energy released per unit time within the pupa is $n$ ergs that released in a similar volume of food will be $0.25 n$.

If the absorption of internally generated radiation is 8 per cent. the resultant dose to the fly will be $0 \cdot 08 n$.

In a continuous medium the dose to a volume of food equal to the pupa will be $0.25 n$, but the dose to the pupa itself will be less than this by the amount of energy generated within that volume of food which would be absorbed by it. If the absorption were 8 per cent. (as in the fly) the pupal dose from the medium would be $0.23 n$ or 2.9 times the dose from ingested $\mathbf{P}^{32}$. If, at the other extreme, the absorption were $3^{8}$ per cent. (the theoretical estimate for a sphere equal in volume to the pupa) the dose from the medium would be $0 \cdot \mathrm{I} 5 n$ or $\mathrm{I} \cdot 9$ times that from ingested $\mathrm{P}^{32}$.

Allowing for the many possible sources of error in the above calculations, the most we can confidently conclude is that, during pupation in the medium, the mutagenic potencies of external and internal $\mathrm{P}^{32}$ will be of the same order of magnitude.

So far no exact quantitative study has been made of the variation in sensitivity of the germ cells though Lüning concluded it was about two-fold. As hyperploid production is a two-event phenomenon its frequency will be expected to vary with the square of the sensitivity and thus exaggerate its variation. It would thus seem appropriate to concern ourselves only with the most sensitive stage and to see what variation in mutation rates would be predicted from this alone. This we will take to be seven days from maturity, or, in the experiment, the day of insemination.

Fig. 3 shows the curve of fig. $2 b$ (mated males) moved seven days to the right. The $\mathrm{Y}$ axis is the mutation rate in arbitrary units. Superimposed on the mutations attributable to ingested $\mathbf{P}^{32}$ are the mutations attributable to irradiation from the medium, firstly before pupation and secondly during pupation. Comparison of figs. I and 3 
shows a striking parallelism. One must conclude that if a prediction of mutation rates based only on the hypersensitive stage gives such a close fit, it must be much the most important mutagenically.*

The most serious discrepancy between the expectation and observation is after the ninth day, when the expected mutation rate is consistently too high. A possible explanation for this is that excessive mating has depleted the gonads of $\mathbf{P}^{32}$ more than the rest of the animal. As the gonadal radioactivity is the most important mutagenically, the gross activity of the fly would lead to an over-estimate of its mutagenic potentiality.

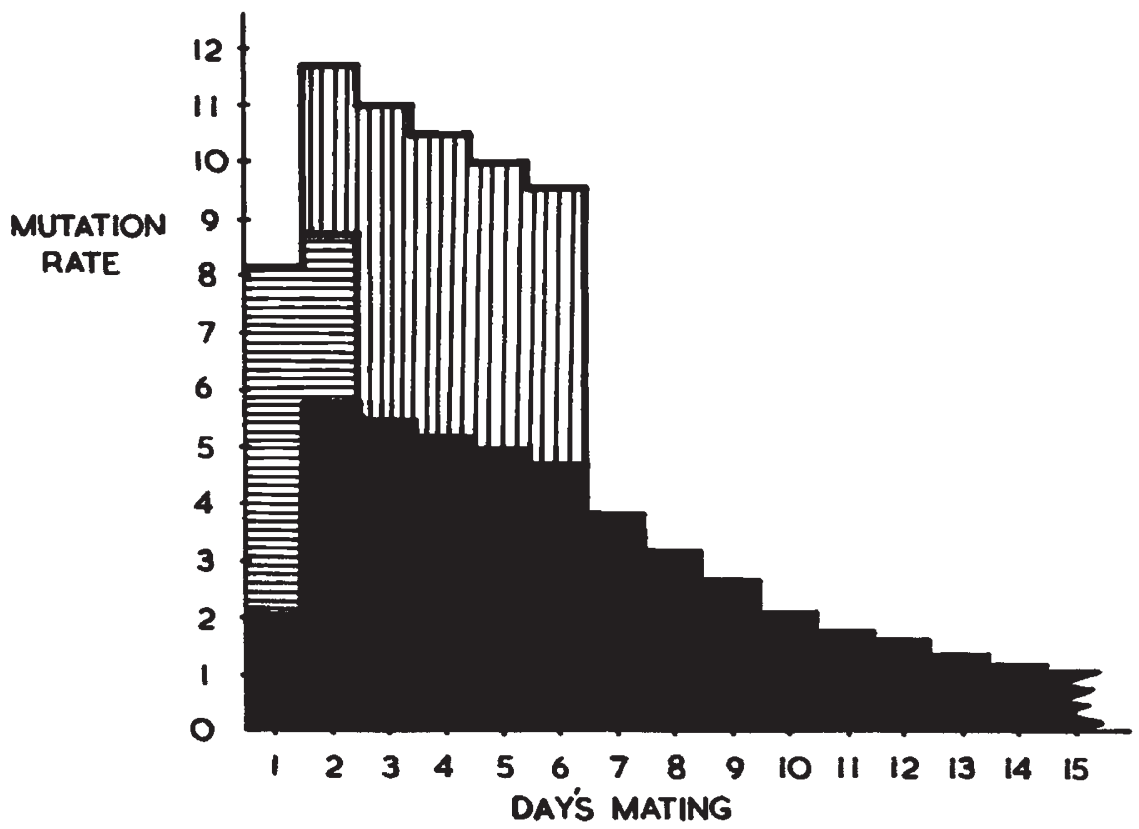

Fig. 3.-Expected mutation rates (arbitrary units) attributable to internal $\mathrm{P}^{32}$ (solid black), to medium external to larvæ (horizontal shading), and to medium external to pupæ (vertical shading), according to successive days' mating. Cf. fig. 1 .

Another discrepancy is that both curves of fig. I should show a peak on the second day as seen in fig. 3. But if the first sperm batches did not reach their hypersensitive stage until after pupation (see Kerkis), prepupal radiation could be neglected. Then the curve for flies pupating out of the medium should show no peak but should start at its maximum. The existing peak is, however, of little importance as it is based on a very small sample (see table 3 ). The curve for flies pupating in the medium, however, should also be high from the beginning. This discrepancy cannot easily be accounted for. Otherwise, the fit between figs. $I$ and 3 is good.

* More recent work by the author, using X-rays, has shown that the increased sensitivity of immature sperm is much greater for hyperploid production than for dominant lethals. In the present studies, therefore, the sensitivity of mature sperm can be ignored. 


\section{VALIDITY OF COMPARISONS OF P32 AND X-RAYS}

The most obvious basis of comparison for the mutagenic actions of $\mathrm{P}^{32}$ and $\mathrm{X}$-rays is their efficiency. But for this one must be able to express the dosages in the same units, such as roentgen. The non-random distribution of $\mathrm{P}^{32}$ makes it out of the question at this stage to estimate the dosage to the gamete chromosomes. Other comparisons that can be made concern the relative frequencies of the different kinds of mutation, which we may call the mutation spectrum, and the effects of the time factor.

As we have seen, the differences between the interactions of $\mathrm{P}^{32}$ and X-rays with time can be attributed solely to the technicalities of the treatments. The action of the $\mathrm{P}^{32}$ is by its very nature continuous and subject to the physiology of the organism. X-rays as normally administered are given at a point in time determined by the experimenter. The effects of $\mathrm{P}^{32}$ as studied above could presumably be reconstructed (laboriously) by a continuous and continually changing dose of X-rays.

The time factor is, however, of importance also to the study of the mutation spectrum, for, as is well known, the so-called " one-hit" changes increase linearly with dose, whilst " two-hit" changes increase with a higher power. Consequently, since the effective dose from the two mutagens changes differently with time, the mutation spectrum will change also. One must therefore restrict comparisons to a welldefined sperm batch, with dosages of $\mathrm{P}^{32}$ and $\mathrm{X}$-rays adjusted to give the same rate for one "band" of the mutation spectrum (say sex-linked lethals).

A further complication has come to light, details of which I shall be publishing shortly. The variation in sensitivity during sperm maturation to one and the same mutagen (X-rays) is markedly different according to the "band" being studied. It is not sufficient therefore to confine one's attention to a single sperm batch. The two mutagens must have acted on the same maturation stage. With $\mathbf{P}^{32}$ and X-rays this would be almost impossible to achieve.

It appears, then, that one can have no confidence in attributing any difference which has been or may in future be revealed between the effects of these two mutagens to the quality of the radiations (such as the transmutation of $\mathbf{P}^{32}$ to $\mathrm{S}^{32}$ ). There are too many other possible sources of difference.

\section{SUMMARY}

1. Preliminary comparisons of the mutagenic effects of ingested $\mathrm{P}^{32}$ and X-radiation of mature sperm showed the need to analyse the variation in the effects of $\mathrm{P}^{32}$ with successive sperm batches.

2. Drosophila males were reared in vials of normal medium to which had been added $30 \mu \mathrm{C}$ of $\mathrm{P}^{32}$ in $0.03 \mathrm{ml}$. of solution twenty-four hours after termination of egg laying. 
3. The mutation rate was measured as the percentage of hyperploid non-yellow daughters on mating irradiated males to fresh attached- $X$ yellow females each day.

4. In males pupating out of the active medium the mutation rate was about constant at 3 per cent. up to the sixth day's mating, when it fell to zero by the ninth day. Males which had pupated in active melium showed an additional peak of 7 per cent. to 8 per cent. on the fourth and fifth days' mating.

5. The $\mathrm{P}^{32}$ content of the males was maximal during pupation. Adults lost their activity rapidly, especially when mated.

6. It was confirmed that there is a hypersensitive stage in spermiogenesis seven days prior to maturity.

7. The absorption of internally generated radioactivity was reassessed at 8 per cent.

8 . The variation in mutation rate with day of mating was predictable from the $\mathrm{P}^{32}$ content of the fly and the extent of external radiation at the moment when each batch was in its hypersensitive stage.

9. During pupation in active medium external and internal radiation were responsible for about equal amounts of mutation.

Io. The difficulties in the way of a valid comparison of the qualitative effects of $\mathrm{P}^{32}$ and X-rays are almost insuperable.

Acknowledgments.- The author wishes to express his appreciation to Dr F. C. Bawden of the Plant Pathology Department, Rothamsted, for permission to use its Geiger counter and to Mr H. L. Nixon of the same Department for assistance and advice with the more physical aspects of the work.

\section{REFERENCES}

AUERbach, c. 1954. Sensitivity of the Drosophila testis to the mutagenic action of X-rays. Z.I.A.V., 86, I 1 3-1 25.

bateman, A. J., AND sinclair, w. K. 1950. Mutations induced in Drosophila by ingested phosphorus-32. Nature, 165, i 1 7-1 18.

KERKIS, J. I933. The development of gonads in hybrids between Drosophila melanogaster and D. simulans. 7. Exp. Zool., 66, 477-509.

KING, R. C. 1952. Calculation of radiation doses to $\mathrm{P}^{32}$ labelled male $D$. melanogaster. Nucleonics, 10, 88-89.

KING, R. C. 1953. Studies with radiophosphorus in Drosophila. I. The mutagenic effectiveness of radioactive phosphorus in adult male D. melanogaster. $\mathcal{7}$. Exp. Zool., 122, 541-575.

LÜNING, K. 1952. X-ray induced dominant lethals in different stages of spermatogenesis in Drosophila. Hereditas, 48, $9^{1-107}$. 